\title{
Ergonomic conditions in manual harvesting in Swedish outdoor cultivation
}

\author{
Stefan Pinzke ${ }^{1, A-F}$, Lillian Lavesson ${ }^{1, A-F}$ \\ ${ }^{1}$ Swedish University of Agricultural Sciences (SLU), AEM \\ A - Research concept and design, B - Collection and/or assembly of data, C - Data analysis and interpretation, \\ $D$ - Writing the article, E - Critical revision of the article, F- Final approval of article \\ Pinzke S, Lavesson L. Ergonomic conditions in manual harvesting in Swedish outdoor cultivation. Ann Agric Environ Med. 2018 ; $25(2)$ : $481-487$. \\ doi: $10.26444 /$ aaem/93334
}

\section{Abstract}

Introduction and objective. Ergonomic problems in manual labour in agriculture are well known worldwide. This study investigates the ergonomic conditions during manual work in Swedish outdoor vegetable/berry cultivation.

Materials and method. A questionnaire on work and health conditions was sent to all growers of vegetables and strawberries in Sweden. Workplace studies with video recordings and observations of work operations and positions at harvest were performed. Calculations of back compression and risk assessment for harmful impact of work were made. Employers and employees were interviewed.

Results. Working standing/walking instead of kneeling when harvesting vegetables was shown to decrease lumbar compression. Using a conveyor belt instead of carrying a plastic box into the field for the harvested vegetables reduced harmful forward bends and the risk of musculoskeletal disorders (MSD). When strawberries were grown in pots, the work position was a straight back and neck, with lowered arms. When grown on raised beds, the work position was either kneeling or bending forward with straight legs. When kneeling, the back was often bent or rotated, frequently with the arms far from the body. Bending forward with straight legs caused a harmful level of lumbar compression.

Conclusions. Harmful work postures arise during manual harvesting in Swedish outdoor cultivation. The risk can be reduced using mechanized work tools and optimal cultivation methods. Adequate work training, including instructions about optimal working postures and movements, may reduce the risk of MSD, but will most likely not eliminate it completely.

Key words

agriculture, ergonomics, horticulture, musculoskeletal disorder, posture analysis, questionnaire

\section{INTRODUCTION}

Musculoskeletal disorders (MSD) are a major problem in working life. The costs to society, companies, and individuals are high $[1,2]$, as is the level of suffering among victims [3-5].

Ergonomic problems in manual labor in agriculture and in horticulture are well known and documented throughout the world [6-9]. Although many tasks have been mechanized and work tools and methods of cultivation have been improved, manual work with bent and twisted postures, such as kneeling and squatting, is often still required. Working in such positions is a known risk factor for MSD [3, 7, 10-14].

Previous studies have shown significant ergonomic problems arising from work in greenhouses [14-17], especially tasks requiring the use of limbs in extreme positions [18]. Many work tasks in cultivation, including manual work in the open field, involve difficult work positions [19-22], creating heavy loads not only on the back, but also on the hips, knees, and feet [23], and arise, e.g. during sowing, planting, weeding, and harvesting.

Field growing can also involve intensive work with repetitive movements, often accompanied by lifting and long hours. Workers performing these tasks in the United States report pain and injuries in the musculoskeletal system more often than average $[4,5]$. In Sweden, there is a lack of knowledge about the ergonomic conditions for employees performing manual tasks in outdoor cultivation.

Address for correspondence: Stefan Pinzke, Swedish University of Agricultural Sciences, SLU, AEM, PO Box 88, SE-23053 Alnarp, Sweden

e-mail: stefan.pinzke@slu.se

Received: 19.04.2018; accepted: 12.07.2018; first published:07.08.2018

\section{OBJECTIVES}

The aim of this study was to determine the ergonomic conditions during manual work in Swedish outdoor cultivation.

The following issues were considered:

- operations that include manual work;

- physical loads that arise;

- occurrence of MSD in workers;

- the way in which work tasks are performed.

\section{MATERIALS AND METHOD}

Survey of employers. A questionnaire aimed at employers with manual work in their outdoor cultivation was distributed in January 2014 through the Swedish Board of Agriculture to all growers of vegetables (760) and strawberries (377) employing field staff in Sweden [24].

The survey included questions on the crops grown on the farm, manual tasks, and cultivated area, and questions about staff, working hours, job rotation, work change, breaks at work, wage form, work clothes, tools, incidence of MSD according to the standardized Nordic questionnaires for analysis of musculoskeletal symptoms [25], and other issues. Reminder cards were sent out after 4 weeks, and a further mailing of the questionnaire was made 10 days later to those who had not yet responded. The responses received were entered into data files. The data were analyzed descriptively using the programme IBM SPSS Statistics for Windows (version 20) [26], and presented in tabular form as numerical value, percentage, mean, and spread. 
Interviews. Interviews were conducted with 5 employers (3 vegetable crop producers, 2 strawberry growers) in Skåne County, southern Sweden, in June, July, and October 2015. The employers were selected based on the criterion that they had employees and that the work (harvesting) was performed manually on the crops currently growing on the farm. The employers or a representative were interviewed about their own experience of manual work on the farm, methods of cultivation and working methods, what could have been changed in the manual work, and their awareness of possible MSD among employees.

During field studies, 10 employees (6 male, 4 female) were interviewed on the vegetable farms, and 5 employees ( 3 male, 2 female) on the strawberry farms. The interviews on these occasions included questions about methods of work, the working environment and working conditions, work experience, instructions for the work, respondent's knowledge of ergonomics, and whether they experienced physical symptoms as a result of their work. None of the interviewed employees had Swedish as their native language. The interviews were conducted in English, partly with the help of supervisors acting as interpreters.

Workplace studies. Workplace studies in the field were conducted in June, July, and October 2015 on the farms of the 6 vegetable employers surveyed, during which postures and movements in the manual harvesting work were observed and videotaped. Three different vegetable plants (cauliflower, broccoli, iceberg lettuce) were chosen, based on high occurrence of manual work at harvest, and each vegetable was studied in 2 different cultures. Manual harvesting of strawberries was also studied in 2 different cultures.

Observations with video camera. Work postures, working techniques, equipment and facilities, etc. were recorded and documented in the different cultures. The video recordings provided input to biomechanical analysis of posture, observation and documentation of the existing work movements, and time estimation of cycles in the harvesting work.

Biomechanical analysis and risk assessment. The physical workloads were analyzed using the ALBA biomechanics computer programme developed at KTH-Royal College of Technology, Sweden [27]. The programme uses a computerized human dummy which has limbs that can be set in different joint positions, and on which body measurements can be taken and possible burden estimated. The ALBA programme was used in this study to calculate the lumbar compression in static positions. The dummy was placed in different positions corresponding to the working positions that the workers adopted during different tasks in the harvesting work, using representative images from the video recordings as the basis.
For length and weight adjustment, the programme's population base for Swedish males $(178 \mathrm{~cm}$ tall and weighing $81 \mathrm{~kg}$ ) and Swedish females (167 cm tall and weighing $63 \mathrm{~kg}$ ) was applied. The calculation of lumbar compression was intended to show the loads the different working positions generated, regardless of the burden.

The results were also assessed in relation to the United States National Institute for Occupational Safety and Health (NIOSH) recommended permissible limit (action limit) of $3400 \mathrm{~N}$, which indicates a need for measures to reduce the risk of MSD [28].

Assessment of physical loads were also carried out, using the Swedish Work Environment Authority's 'Checklist Ergonomics', which assesses the risk of adverse effects of work postures and movements [29]. This is a risk assessment which takes the whole body into account, and where the work movements and postures assessed are expected to take place for a substantial part (7-8 hours) of the working day. The checklist is based on the Authority's regulations and general advice on ergonomics (AFS2012-2) [30].

\section{RESULTS}

Survey. In total, 472 vegetable growers (62\%) responded, of whom 192 were employers, and 230 strawberry growers (61\%) responded, of these, 118 were employers. $50 \%$ of the vegetable grower-employers had a cultivated area of 2 ha or less and $3 \%$ had more than 50 ha, while $25 \%$ of the strawberry grower-employers had an area less than 1 ha and $10.5 \%$ had an area more than 10 ha (Tab. 1).

The vegetable employers had an average of 7 employees, with the number ranging from 1-69, of which $37 \%$ were females and 63\% males (Tab. 1). The strawberry growers had an average of 20 employees, with the number ranging from 1-250, of whom 55\% were females and $45 \%$ males (Tab. 2).

Two variables formed the selection basis for the vegetable crops chosen for study: 1) a high proportion of manual work

Table 2. Proportion (\%) of manual work for different crops during planting, weeding, and harvesting in outdoor cultivation

\begin{tabular}{lccc}
\hline & Planting & Weeding & Harvesting \\
\hline Cauliflower & 18 & 46 & 100 \\
\hline Broccoli & 52 & 58 & 94 \\
\hline White cabbage & 40 & 56 & 100 \\
\hline Other brassicas & 67 & 74 & 94 \\
\hline Iceberg lettuce & 20 & 40 & 100 \\
\hline Other legumes & 67 & 67 & 78 \\
\hline Cucumber & 58 & 86 & 100 \\
\hline Squash & 83 & 75 & 92 \\
\hline
\end{tabular}

Table 1. Summary of responses from employers growing vegetable plants and strawberries

\begin{tabular}{|c|c|c|c|c|c|c|c|c|c|c|}
\hline & \multicolumn{5}{|c|}{ Vegetables } & \multicolumn{5}{|c|}{ Strawberries } \\
\hline & $N$ & Min & Max & Mean & $S D$ & $N$ & Min & Max & Mean & $S D$ \\
\hline Cultivated area (ha) & 187 & 0.01 & 148 & 9.2 & 19.56 & 115 & 0.03 & 100 & 6.9 & 14.29 \\
\hline No. of employees & 182 & 1 & 70 & 7.4 & 11.06 & 112 & 1 & 250 & 20.4 & 35.67 \\
\hline Age of employees (years) & 173 & 15 & 80 & 38.0 & 14.31 & 110 & 15 & 81 & 33.4 & 13.59 \\
\hline Proportion of females (\%) & 175 & 0 & 100 & 37.5 & 27.58 & 108 & 0 & 100 & 54.9 & 22.26 \\
\hline
\end{tabular}




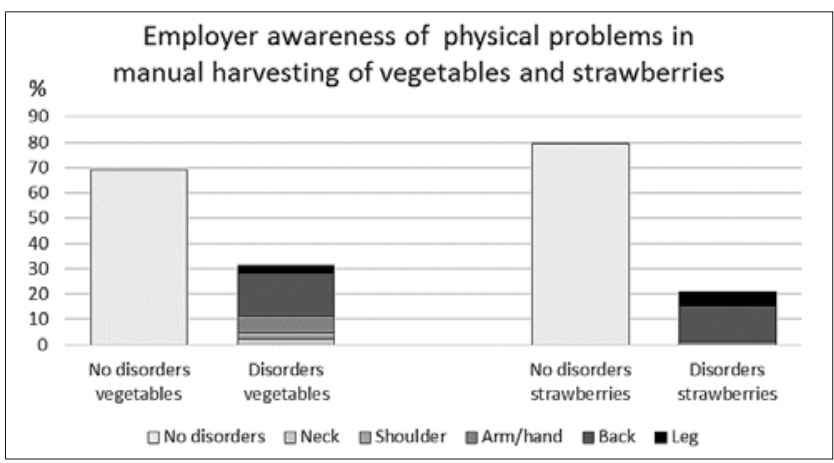

Figure 1. Employer awareness of physical disorders among employees during manual harvesting of vegetable crops $(\mathrm{N}=175)$ and strawberries $(\mathrm{N}=105)$ and where appropriate, the body part affected

and 2) this work continuing for a long period of time (Tab. 2). Based on this, harvesting of cauliflower, iceberg lettuce, and broccoli was studied. Almost one-third of vegetable groweremployers (31\%) reported knowledge of physical problems in manual harvesting work among their employees. Back disorders were most frequently reported (91\%), followed by arm/hand problems (Fig. 1).

Harvesting strawberries was also chosen to be studied, since it is known to have difficult work positions. One in 5 strawberry growers $(21 \%)$ reported knowledge of physical discomfort due to manual harvesting work among their employees. Back pain disorders were most frequently reported (85\%), followed by leg and arm/hand problems (Fig. 1).

In all, $50 \%$ of vegetable growers and $41 \%$ of strawberry growers reported having personal experience of physical discomfort from such manual work.

The survey revealed that $93 \%$ of employers schedule pauses during the working day, while 55\% take actions such as reduced working hours, adaptation of individual tasks, extra breaks, and job rotation. However, 30\% still reported that harvesting has intensive periods when the working day is longer than 8 hours.

A lower proportion, 40\%, of strawberry employers reported that they take measures on working arrangements, such as short working days, breaks, and job rotation, while 33\% arrange job rotation between picking and other tasks, 36\% shift between work tasks and crops on the farm, and 19\% reported job rotation over the season. Around $12 \%$ of growers did not write anything about how the work rotation was designed. Of the total responding, $67 \%$ provide various tools, such as carts for strawberry cartons, and protective clothing such as knee pads/protection, shoes, pants, rainwear, boots, and gloves.

$60 \%$ of vegetable grower-employers and $50 \%$ of strawberry grower-employers provided job introduction, but did not report whether or not it contained ergonomic information to the employees. However, 25\% of grower-vegetable employers and $20 \%$ of strawberry grower-employers expressed a need for more ergonomic knowledge about manual work in the form of short courses and information material.

Interviews. Interviews with employers/supervisors of vegetable and strawberry pickers revealed that they were aware that the manual work could cause physical complaints among employees. They also had personal experience of physical problems especially in the back and shoulders. They were aware of the importance of working time with appropriate breaks, but the harvesting periods had peaks, depending on crops, weather, and demands from buyers. The working day could therefore be longer than 8 hours.

Almost all employers reported that they give a job introduction to their employees. It contains information about the work and the importance of obtaining a 'good' end product; appearance, maturity, etc.

All workers in the field studies were employed by the growers and most of them came from European countries other than Sweden.

Six out of the 10 interviewed employees harvesting vegetables reported MSD such as neck, back, shoulder, wrist/ hand, and/or feet/ankle disorders.

All (5) employees harvesting strawberries interviewed reported MSD in the form of back pain and knee and/or shoulder problems.

\section{FIELD STUDIES}

Harvesting vegetables. The vegetables cauliflower, broccoli, and iceberg lettuce were all grown on machine-raised beds, and 2 different harvesting methods were observed. In one, the vegetables were placed in a box carried out into the field or placed in the bed (Fig. 2 and 3, upper line). In the other, the vegetables were placed on a conveyor belt or in a box on a tilted arm in the field (Fig. 2 and 3, lower line). Representative parts of the different harvesting methods were analyzed and compared in terms of work movements, work postures, back compression, risk of MSD, and time spent per harvested unit.

The observed work cycle and positions for a field worker using the different harvesting methods can be summarized as:

1) carrying a box (Fig. 2, upper line): bending deeply forward twice in the work cycle and remaining slightly bent forward all the time;

2) using a conveyor belt (Fig. 2, lower line): bending deeply forward once, but in the other positions straightening up;

3) placing a box on the bed (Fig. 3, lower line): bending deeply forward once, rotating the back strongly once, but also straightening-up in- between;

4) placing boxes on a tilted arm in the field (Figure 3, upper line): bending deeply forward once, but otherwise standing up straight.

Calculation of back compression when harvesting vegetables. Regardless of the working method, one deep bending forward movement was seen in the work task 'Cut'. The ALBA analysis of this position showed back compressive forces over $3000 \mathrm{~N}$, which is close to NIOSH $3400 \mathrm{~N}$, an action level describing the need for changes to reduce the risk of MSD.

This deep bending forward occurred twice when carrying a box into the field.

Risk assessment of harmful work positions and work movements. Several workers are at risk of MSD when harvesting vegetables, regardless of work methods, based on the frequent repetition of deep forward bends with back compressive forces at levels above $3000 \mathrm{~N}$.

However, when carrying a box into the field most workers are at a higher risk, based on even more frequent forward bends and also lifting/carrying the box. 


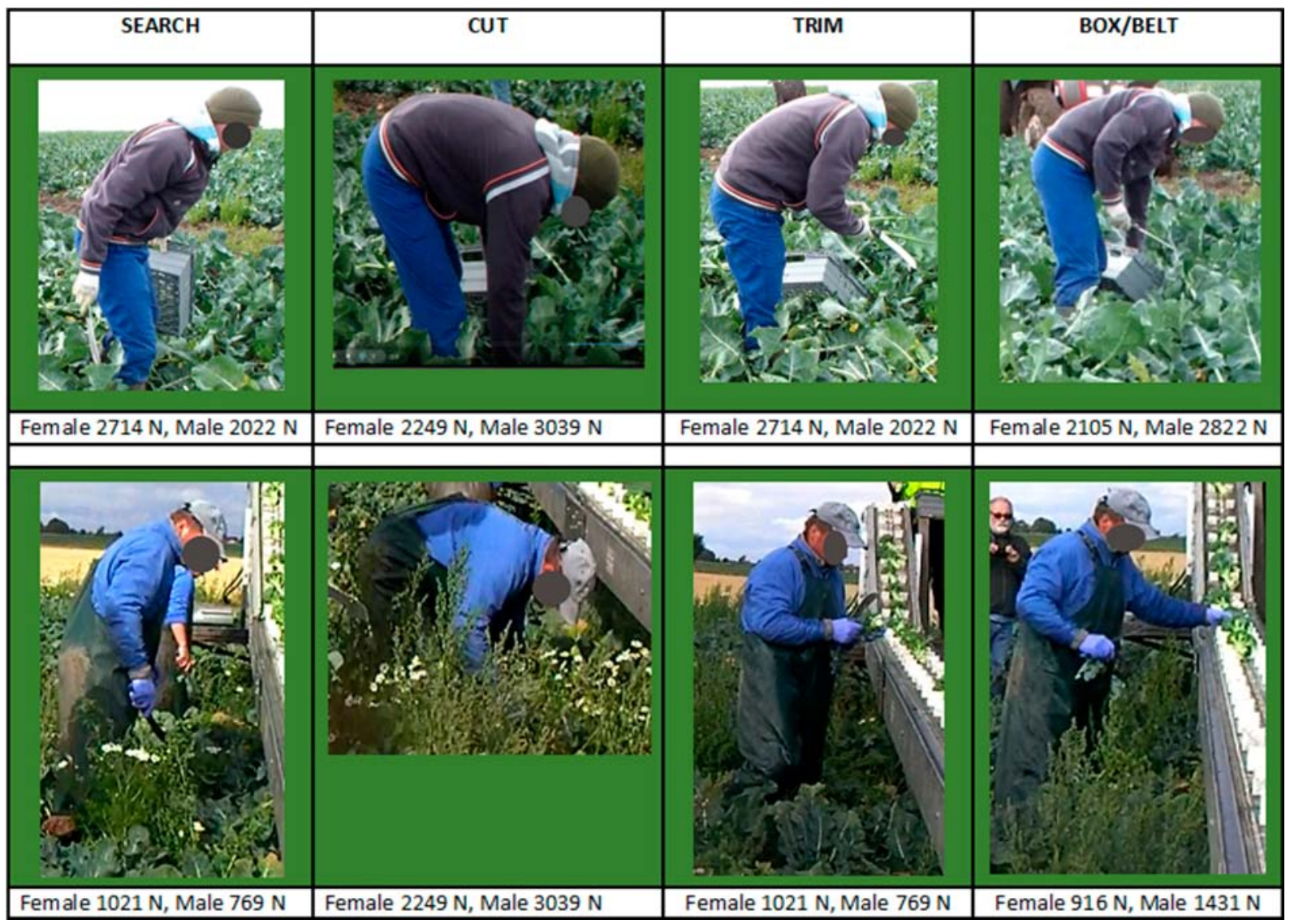

Figure 2. Working positions during harvesting of broccoli/cauliflower using a box (above) and using a conveyor (below). Calculated lumbar compression (N) for males and females in different work positions is given under the images

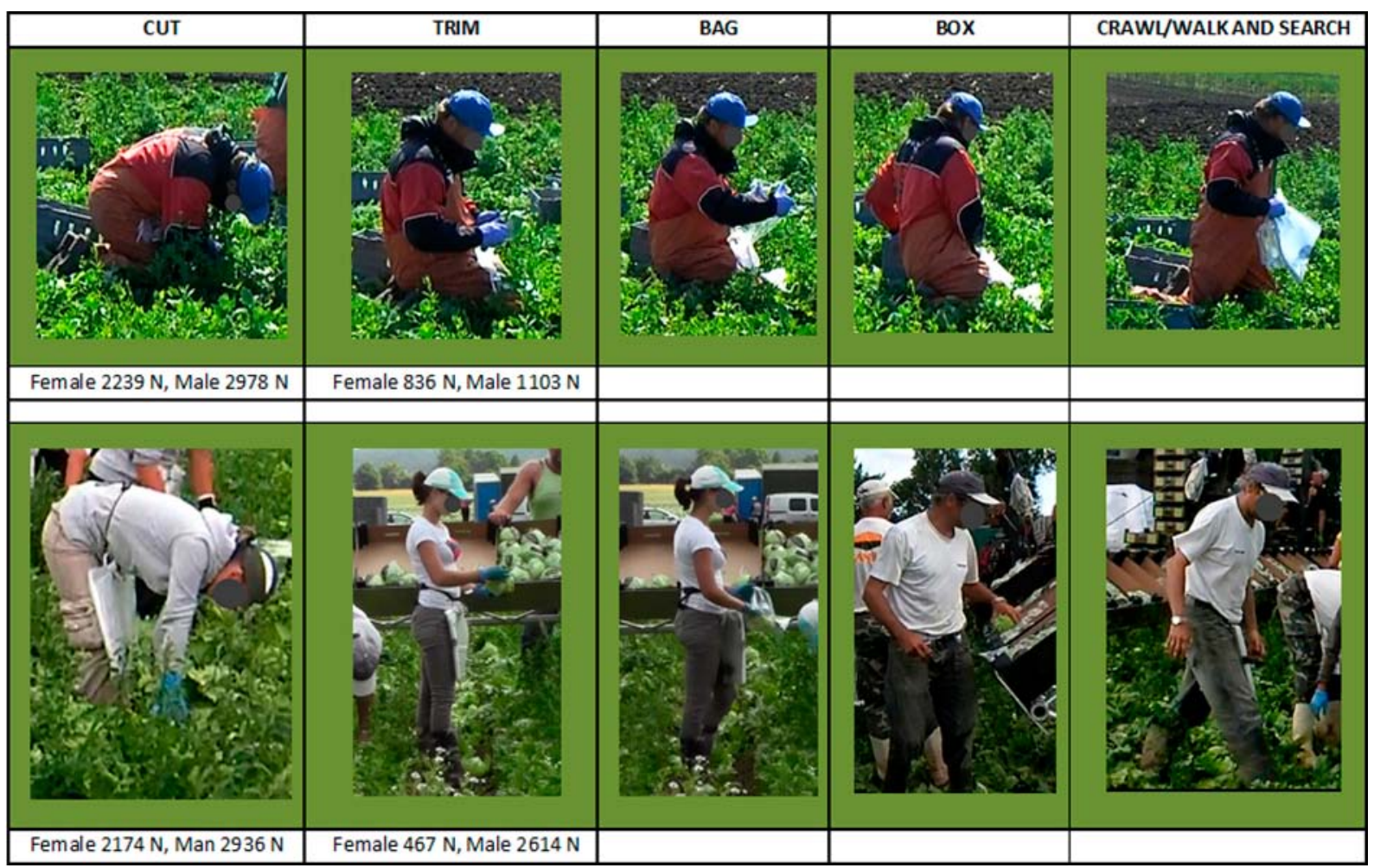

Figure 3. Working positions during harvesting of iceberg lettuce using a box on the plant bed (above) and using a box on a tilted arm (below). Calculated lumbar compression $(\mathrm{N})$ for men and women in different work positions is given under the images 
In a kneeling work position (Fig. 3, upper line), most workers are at a higher risk of $M S D$, based on the level of back compression, repeated back twists and turns, and the locked posture of the legs.

Estimated time spent per harvested vegetable plant for the different work methods. The time estimations from the video recordings showed that when using a conveyor belt or box on a tilted arm, the workers harvested significantly more vegetable plants (70-110\% more) in a set period than when carrying a box into the field or having the box on the ground (Tab. 3).

Table 3. Work sequences, analyzed from video films by calculating time per unit in harvesting vegetables

\begin{tabular}{lcccc}
\hline Vegetable & $\begin{array}{c}\text { Times/ } \\
\text { work } \\
\text { cycle }\end{array}$ & $\begin{array}{c}\text { No. of } \\
\text { units/ } \\
\text { work } \\
\text { cycle }\end{array}$ & $\begin{array}{c}\text { Mean } \\
\text { times } \\
\text { /unit }\end{array}$ & $\begin{array}{c}\text { No. } \\
\text { of } \\
\text { units/ } \\
\text { hour }\end{array}$ \\
\hline Cauliflower - harvesting into box on ground & 234 & 12 & 19.5 & 185 \\
\hline Cauliflower - harvesting onto conveyer belt & 9 & 1 & 9 & 400 \\
\hline Broccoli - harvesting into box on ground & 369 & 21 & 17.6 & 205 \\
\hline Broccoli - harvesting onto conveyer belt & 135 & 13 & 10.3 & 350 \\
\hline Iceberg lettuce - harvesting into box on ground & 18.5 & 1 & 18,5 & 195 \\
\hline Iceberg lettuce - harvesting into box on arm & 11 & 1 & 11 & 330 \\
\hline
\end{tabular}

Harvesting strawberries. Three different cultivation methods of strawberries were observed and analyzed:

1) harvesting strawberries grown on flat ground: The worker placed cardboard boxes directly on the ground and squatted down with one knee on the ground (Fig. 4, picture 2). They picked berries both to the right and to the left, rose and moved to new plants, sat 'huddled' with rounded back and sharply bent at hip, knee, and ankle joints, sometimes with twisted back, and movements with arms far out from the body;

2) harvesting strawberries cultivated on machine-raised bed: The worker took a crate with 15 cardboard boxes, went to the assigned strawberry rows, and placed it down on a carriage, which was manually rolled forward when needed. Berries were picked both to the left and right and, when all cartons were filled, the crate with the berries (weight $8 \mathrm{~kg}$ ) was carried to a collection point. It took about 20 minutes to fill 15 cartons, and the walk back and forth took about 10 minutes.
Most of the workers knelt on both knees in the furrow between the beds (Fig. 4, picture 3). They stretched forward/ inward over the plants, often twisted in the back and sometimes with their arms far out, some shifting between left and right knee, some moving into the direction in which they were picking. This was observed to decrease twists in the back compared with being 'stuck' in a kneeling position.

A few of the workers were observed standing, bending forwards with straight legs, (Fig. 4, picture 4) when picking, and remained bending forward until all 15 cartons were filled.

3) Harvesting strawberries cultivated in pots in a tunnel: The worker took a crate with 15 cardboard boxes, went to the assigned strawberry rows, and placed it on a carriage. Berries were picked both to the left and right, and the worker was observed standing straight, turned towards the plants, and most often with arms lowered and close to the body (Fig. 4, picture 1) when picking. The carriage was manually rolled forward.

Calculation of back compression during harvesting of strawberries. The ALBA analysis showed high back compression levels, calculated at $3000 \mathrm{~N}$, for strawberry pickers when standing, bending forward with straight legs (Fig. 4, picture 4). When squatting with one knee on the ground, the compression was calculated to be $2700 \mathrm{~N}$. Kneeling (Fig. 4, picture 2) or standing with a straight back (Fig. 4, picture 1) showed low back compression.

Risk assessment of harmful work positions and work movements. No workers are at risk of MSD when picking strawberries grown in pots, standing straight in neck and back, with lowered arms and shoulders.

Several workers are at risk of MSD in frequent work, kneeling with frequent forward and side bends, twists in the back, and arms far out from the body.

Consideration was taken of having a 10 -minute walk as an interruption every 20 minutes.

Most workers are at risk of MSD during frequent work when standing bending forward with straight legs, or when sitting or squatting with one knee on the ground.

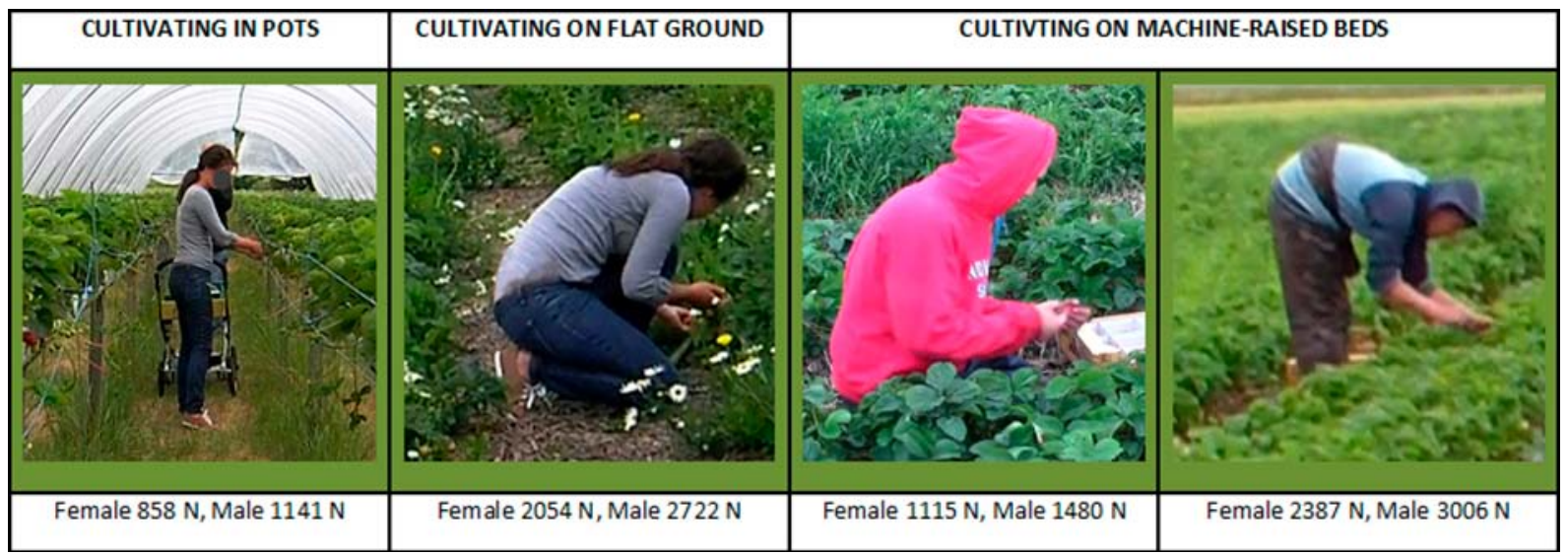

Figure 4. Working positions when harvesting strawberries cultivated in pots, on flat ground, and on machine-raised beds; 2 different work positions shown. Calculated lumbar compression $(\mathrm{N})$ for men and women in different work positions is given under the images 


\section{DISCUSSION}

This survey showed a high incidence of manual work in open fields, particularly when harvesting strawberries and some vegetables. Several species of vegetables are now harvested by machine and technological development is underway, but it has not been possible to replace all manual harvesting.

This study showed that manual harvesting posed a major risk of MSD. Difficult work positions were noted that may cause musculoskeletal problems according to AFS regulation 2012:2 [30], but the risks can be reduced by choosing adequate cultivation and harvesting methods.

Using conveyor belts in the field or tilted boxes on a fixed arm involved half the number of bends forward, compared with having or carrying a box on the field. This reduced the overall back load by more than $50 \%$. When carrying a box in the field, the employees often remained in the forward bending position in the various work elements, which increased the overall back load.

When using conveyor belts and fixed-arm tilted boxes, the workers harvested more units per hour than when working with a plastic crate. This can be a factor justifying the cost, implementation, and use of these work aids. However, even the best work methods observed exerted excessive back compression levels and were considered to pose a risk of MSD. To reduce the risk, the working hours of employees in these jobs need to be reduced. In reality, the opposite was observed, with employees sometimes working more than 8 hours a day.

Attempts are being made, e.g., to develop taller vegetable plants and thus reduce the need for deep back bends when harvesting. Efforts have also been made to design aids that can relieve the load on the back and thereby reduce back compression. It is important to continue developing work aids and methods in order to reduce the workload.

In strawberry picking, the cultivation method used proved to be of the greatest importance. Strawberries planted in pots are preferable from the ergonomic point of view, as deep back bends are eliminated. Today, strawberry cultivation in raised beds is most common on larger areas [31]. In harvesting work with this type of culture, individual variations were observed, as were work positions that had a bearing on the physical strain. The most common work posture was kneeling, causing the knees and feet to be bent in their most extended positions. Kneeling, squatting, or resting on one knee when harvesting vegetables or strawberries means a risk of joint discomfort [32-34]. It is also a locked posture, and the worker tries to compensate for the limited mobility with neck and back twists, as well as working with the arms far out from the body. The work method for strawberry picking where workers picked for 20 minutes and walked for 10 minutes was an attempt to compensate for the locked seat position.

It is also important to be aware of how dynamic but frequent arm work, especially for females, can lead to static strain, with muscular pain and fatigue and an increased risk of MSD [3]. Employers prefer female pickers because 'they pick better and gently'. This emphasizes how the choice of cultivation method has a huge impact on the risk of MSD.

It was observed that individual workers had adopted their own ways to work, finding both good work positions and risky positions, such as bending forward with straight legs. This work position must and can be avoided. It is essential that workers have access to adequate ergonomic advice and information, in order to alleviate the physical strain and load from manual harvesting, which $25 \%$ of growers also wanted. A mentoring system in the workplace, where experienced employees can guide and support new employees, can be helpful. Obtaining knowledge can reduce the work load, but NOT eliminate it!

Working outdoors during manual harvesting is not just about working posture and ergonomics. It is also about the climate that can increase the load and be a safety risk [35]. Working in cold or hot environments increases the risk of accidents and injuries $[9,15,16,35-38]$. Today, it is important to avoid exposure to the sun and use sunscreen to prevent health problems. Lack of supportive workplaces or knowledge may be reasons why it is not always used [39].

The results of the presented study add to current knowledge on the difficult ergonomic situation in manual harvesting at and below knee height. In-depth ergonomic knowledge is needed about all manual working positions and workloads in outdoor cultivation. Continued development of work and cultivation methods, such as work tools, is necessary to achieve a work situation that avoids the risks of both temporary and permanent MSD.

\section{CONCLUSIONS}

- The work methods and work aids used when harvesting cauliflower, broccoli, and iceberg lettuce proved to be of crucial importance for the workload on the employee's back and the risk of MSD.

- The cultivation method used for strawberries was of crucial importance for the total workload and the risk of MSD.

- The choice of work position in strawberry picking proved to be of great importance for the risk of MSD.

- Employers need to be informed about methods of cultivation.

- Employers and workers need to be informed about ergonomics, ways of working, and work aids.

\section{REFERENCES}

1. Balogh I. Exposure Assessment for the Prevention of Musculoskeletal Disorders. [dissertation]. Lund University, Lund, Sweden; 2001.

2. Buckle PW, Devereux JJ. The nature of work-related neck and upper limb musculoskeletal disorders. Appl Ergon. 2002; 33: 207-217.

3. Kuorinka I, Forcier L, Hagberg M, Silverstein B, Wells R, Smith MJ, et al. Work related musculoskeletal disorders (WMSDs): A Reference Book for Prevention. London: Taylor \& Francis; 1995.

4. Osorio AM, Beckman J, Geiser CR, Husting EL, Inai A, Summerill KF. California farm survey of occupational injuries and hazards. J Agric Saf Health. 1998; 99(1): 99-108.

5. US Department of Labor. Occupational Injuries and Illnesses in the United States by Industry, 1992-2001. Bureau of Labor Statistics; 2002.

6. Gemma SFB, Tereso MJA, Abrahão RF. Complexity and ergonomy: the manager work at the organic agriculture in Campinas - SP Brazil Cienc. Rural [online]. 2010; 40(2): 288-294.

7. Lee S-J, Park HJ. Work-related Musculoskeletal disorders among Agricultural Workers. J Ergon Soc Korea. 2011; 30(4): 525-534.

8. Abrahão RF, Ribeiro IAV, Tereso MJA. Workload composition of the organic horticulturea. Work. 2012; 41: 5355-5360.

9. Xiang J, Bi P, Pisaniello D, Hansen A, Sullivan T. Association between high temperature and work-related injuries in Adelaide, South Australia, 2001-2010. Occupational Environment Med. 2014; 71: 246-252.

10. Amstrong TJ, Buckle P, Fine LJ, Hagberg M, Jonsson B, Kilbom A, et al. A conceptual model for work-related neck and upper-limb musculoskeletal disorders. Scand J Work Environment Health. 1993; 19: $73-84$. 
11. Bernard BP. Musculoskeletal disorders and workplace factors: a critical review of epidemiological evidence for work-related musculoskeletal disorders of the neck, upper extremity, and low back. DHHS (NIOSH) publication no. 97-141. Cincinnati, OH: U.S. Department of Health and Human Services, Public Health Service, Centers for Disease Control and Prevention, National Institute for Occupational Safety and Health; 1997.

12. National Research Council and Institute of Medicine. Musculoskeletal Disorders and the Workplace: Low Back and Upper Extremities. Panel on Musculoskeletal disorders and the Workplace. Washington, DC: National Academy Press; 2001.

13. Punnett L, Wegman DH. Work-related musculoskeletal disorders: the epidemiologic evidence and the debate. J Electromyogr Kinesiol. 2004; 14(1): 13-23.

14. López-Aragón L, López-Liria R, Callejón-Ferre A-J, Pérez-Alonso J. Musculoskeletal disorders of agricultural workers in the greenhouses of Almería (Southeast Spain). Saf Sci. 2018; 109: 219-235.

15. Chad KE, Brown JMM. Climatic stress in the workplace: Its effect on thermoregulatory responses and muscle fatigue in female workers. Appl. Ergonomics. 1995; 26(1): 29-34.

16. Hancock PA, Ross JM, Szalma JL. A Meta-Analysis of Performance Response Under Thermal Stressors. University of Central Florida, Hum. Factors. 2007; 49(5): 851-877.

17. Callejón-Ferre A, Pérez-Alonso J, Sánchez-Hermosilla J, CarreñoOrtega J. Ergonomics and psycho-sociological indices in greenhouses, Almeria (Spain). Span J Agric Res. 2009; 7(1): 50-58.

18. Lundqvist P, Pinzke S, Kyrö Wissler S, Stål M. Åtgärdsprogram för en god arbetsmiljö inom trädgårdsnäringen. [Action program for a good working environment in the horticulture industry]. Report, Stiftelsen Lantbruksforskning (SLF); 2008. http://www.lantbruksforskning. se/projektbanken/atgardsprogram-for-en-god-arbetsmiljo-inomtradgar $/$ ? page $=1 \&$ sea $\mathrm{ch}=\% \mathrm{C} 3 \% \mathrm{~A} 5 \mathrm{tg} \% \mathrm{C} 3 \% \mathrm{~A} 4 \mathrm{rdsprogram} \& \mathrm{a}$ pp_year $=\&$ category $=\&$ pub_year $=$. Published July 15, 2008. (access: 2018.04.11)

19. Davis KG, Kotowski SE. Understanding the ergonomic risk for musculoskeletal disorders in the United States agricultural sector. Am J Ind Med. 2007; 50(7): 501-511.

20. Kirkhorn SR, Earle-Richardson G, Banks RJ. Ergonomic risks and musculoskeletal disorders in production agriculture: recommendations for effective research to practice. J Agromedicine. 2010; 15: 281-299.

21. Fathallah FA, Meyers JM, Janowitz I. Stooped and Squatting Postures in the Workplace, Center for Occupational and Environmental Health, Proceedings of the Symposium for Stooped and Squatting Posture in the Workplace, Jul. 29-30, 2004; Oakland, USA.

22. Fathallah FA. Musculoskeletal disorders in labor-intensive agriculture. Appl Ergon. 2010; 41(6): 738-743.

23. Jin S, McCulloch R, Mirka GA. Biomechanical evaluation of postures assumed when harvesting from bush crops. Int J Ind Ergon 2009; 39: 347-352.

24. Swedish Board of Agriculture. Trädgårdsproduktion 2011. [The 2011 Horticultural census]. JO 33 SM 1201. https://www.jordbruksverket. se/webdav/files/SJV/Amnesomraden/Statistik, \% $20 \mathrm{fakta} /$ Tradgardsodling/JO33/JO33SM1201_korrigerad_2/JO33SM1201_ ikortadrag.htm Published September 3, 2012. (access: 2018.04.11).
25. Kuorinka I, Jonsson B, Kilbom Å, Vinterberg H, Biering-Sörensen F, Andersson G, et al. Standardised Nordic questionnaires for the analysis of musculoskeletal symptoms. Appl Ergon. 1987; 18(3): 233-237.

26. IBM SPSS Statistics for Windows, Version 20.0. Armonk, NY: IBM Corp; 2011.

27. Vogel K. ALBA - program för biomekanik och antropometri. KTH Royal Institute of Technology, Stockholm, Sweden; 2013. https://www. kth.se/sv/mth/ergonomi/framtagna-verktyg/alba/alba-program-forbiomekanik-och-antropometri-1.54608. Published November 18, 2013. (access: 2018.04.11)

28. Waters TR, Putz-Anderson V, Garg A. Applications manual for the Revised NIOSH Lifting Equation. DHHS(NIOSH) Publication No. 94-110. National Institute for Occupational Safety and Health, Centers for Disease Control and Prevention. Cincinnati, Ohio; 1994.

29. Swedish Work Environment Authority. Checklista Belastningsergonomi. [Checklist - Ergonomics]. Swedish Work Environment Authority, Stockholm, Sweden; 2013. https://www. av.se/arbetsmiljoarbete-och-inspektioner/publikationer/checklistor/ Published August, 2013. (access: 2018.04.11).

30. Swedish Work Environment Authority. Arbetsmiljöverkets föreskrifter och allmänna råd om belastningsergonomi, AFS 2012:2. [Ergonomics for the Prevention of Musculoskeletal Disorders, AFS 2012:2, provisions]. Swedish Work Environment Authority, Stockholm, Sweden; 2012. https://www.av.se/arbetsmiljoarbete-och-inspektioner/publikationer/ foreskrifter/belastningsergonomi-afs-20122-foreskrifter/ Published June 1, 2012. (access: 2018.04.11).

31. Svensson B, Nilsson T, Håkansson B \& Persson M. Substratodlade jordgubbar [Substrate-grown strawberries]. projekt nr 36 i Tillväxt Trädgård 2009-2010. Sveriges lantbruksuniversitet. Landskap trädgård jordbruk. Technical Report 2011: 5; 2011.

32. Manninen P, Heliövaara M, Riihimäki H, Suomalainen O. Physical workload and the risk of severe knee osteoarthritis. Scand J Work Environ Health. 2002; 28(1): 25-32. doi:10.5271/sjweh.643.

33. McMillan G, Nichols L. Osteoarthritis and meniscus disorders of the knee as occupational diseases of miners Occup Environ Med. 2005; 62: 567-575. doi: 10.1136/oem.2004.017137.

34. Jensen, LK. Knee osteoarthritis: influence of work involving heavy lifting, kneeling, climbing stairs or ladders, or kneeling/squatting combined with heavy lifting. Occup Environ Med. 2008; 65: 72-89. doi:10.1136/oem.2007.032466.

35. Lucas RAI, Epstein Y, Kjellstrom T. Excessive occupational heat exposure: a significant ergonomic challenge and health risk for current and future workers. Extrem Physiol Med. 2014; 3: 14.

36. Basu R. High ambient temperature and mortality: a review of epidemiologic studies from 2001 to 2008. Environ Health. 2009; 8: 40.

37. Anttonen H, Pekkarinen A, Niskanen J. Safety at Work in Cold Environments and Prevention of Cold Stress. Ind. Health. 2009; 47: 254-261.

38. Zhao J, Zhu N, Lu S. Productivity model in hot and humid environment based on heat tolerance time analysis. Build. Environ. 2009; 44(11): 2202-2207.

39. McCool JP, Reeder AI, Robinson EM, Petrie KJ, Gorman DF. Outdoor Workers' Perception of the Risks of Excess Sun-Exposure. J Occup Health. 2009; 51(5): 404-411. 